\title{
Influence of daylength experienced by dams on post-natal development of young meadow voles (Microtus pennsylvanicus)
}

\author{
T. M. Lee, L. Smale, I. Zucker and J. Dark \\ Department of Psychology, University of California, Berkeley, CA 94720, U.S.A.
}

\begin{abstract}
Summary. Meadow voles born to dams kept in short days (SD) beginning 5 or 11 weeks before parturition (SD-5, SD-11) had less developed testes, gained weight more slowly and built larger nests than did young gestated and maintained in long days (LD). Pelage development was greater in SD than in LD young at 21 and 45 days of age. At weaning, SD-5 young had less dense fur and shorter guard hairs than did SD-11 young, indicating that the photoperiodic history of dams before insemination affects the postnatal pelage development of their progeny. Short daylengths experienced by dams before mating may facilitate winter preparedness of their offspring.
\end{abstract}

\section{Introduction}

The breeding season of the meadow vole, Microtus pennsylvanicus, typically begins in April and extends until October or November (Christian, 1980). Upon weaning, young voles born in the fall, unlike those born in the spring, must contend with several months of low ambient temperatures and a lack of fresh vegetation (Iverson $\&$ Turner, 1974). Somatic growth and sexual maturation are delayed in fall- as compared to spring-born voles; animals born after the summer solstice do not achieve full maturation until the next spring, at which time they are over 6 months old. By contrast, spring-born cohorts reach full maturity by 2 months of age. The pattern of delayed somatic growth and inhibition of reproductive development for individuals born late in the breeding season has been documented in several small temperate-zone mammals (e.g. Martinet \& Spitz, 1971; Negus et el., 1986).

Daylength, the most accurate predictor of phase within the annual geophysical cycle, is the proximate factor most often used by voles to control seasonal cycles of growth and reproduction (Lecyk, 1962; Grocock \& Clarke, 1974; Pistole \& Cranford, 1982). Short daylengths inhibit growth and delay puberty in $M$. montanus, $M$. arvalis, $M$. agrestis and $M$. pennsylvanicus (Martinet \& Spitz, 1971; Petterborg, 1978; Pistole \& Cranford, 1982; Spears \& Clarke, 1986). Daylengths experienced by dams during gestation affect post-natal rates of development of offspring (Horton, $1984,1985)$. So far there has been no evaluation of the extent to which differences in the number of short days experienced by dams before mating might affect development of young.

The influence of daylength on pelage and nest-building of adult meadow voles has been documented (Dark \& Zucker, 1983), but the role of photoperiod during gestation and early post-natal life on prepubertal development of these traits has not been examined. This issue is of significance because voles weaned in November or December presumably would benefit from increased fur thickness and increased nest-building activity induced by short daylengths. However, it requires about 4 weeks for short daylengths to influence nest building and 8 weeks for pelage to be affected (Dark \& Zucker, 1983; Lee et al., 1987a); if such latencies also apply to young voles, changes in nest-building and pelage would not occur until several weeks after weaning, and would not assist young voles at the time they first begin independent existence. 
The present experiment tested the hypothesis that preparations for overwintering begin during gestation. More specifically, we assessed the influence of daylength during gestation and lactation on post-natal somatic development. We measured body weight, food intake, nest-building, pelage development and reproductive status because each of these probably affects overwinter survival (Gebczynska \& Gebczynski, 1971; Fairbairn, 1977; Dark \& Zucker, 1983; McClure \& Porter, 1983). We also determined whether the number of short days experienced by dams before insemination affected winter preparedness of their offspring.

\section{Materials and Methods}

Adult female voles maintained in $14 \mathrm{~h}$ light/day from birth were housed singly in cages and randomly assigned to light-tight, ventilated cabinets maintained at $23 \pm 2^{\circ} \mathrm{C}$. Cabinets were illuminated with fluorescent lights for $14 \mathrm{~h}$ (long days; LD, lights on 07:00 h) or 10 h (short days; SD, lights on 07:00 h). After females had been in the SD photoperiod for 2 or 8 weeks they were mated by introducing a fecund LD male to each cage for 1 week. At the time of parturition, females had been maintained in short daylengths for 5 or 11 weeks (SD-5 and SD-11). Females housed in LD were mated with LD males. Time of parturition was determined by daily examination of pregnant females at 08:00 and 16:00 $\mathrm{h}$. The number of young per litter was not adjusted since a preliminary study indicated that daylength did not affect this value.

Offspring $(\mathrm{N}=132)$ were weighed $( \pm 0.1 \mathrm{~g})$ between 24 and $48 \mathrm{~h}$ after birth, individually marked and sexed at 10 days of age, and weighed twice weekly thereafter. Litters were weaned at 21 days of age and the young were housed individually or in same-sex litter-mate pairs. Each group (LD, SD-5 and SD-11) consisted of young from 10-14 separate litters and sample size for each sex was 16-26 young per group.

At weaning each young was lightly anaesthetized with halothane and hair depth from pelage surface to skin surface was measured to the nearest $0.1 \mathrm{~mm}$ with a micrometer (McClure \& Porter, 1983); relative hair density was determined by weighing hair shaved from a $1 \mathrm{~cm}^{2}$ patch (Al-Khateeb \& Johnson, 1971), and guard and under hair lengths were measured to the nearest 0.1 mm (Dark \& Zucker, 1983; McClure \& Porter, 1983). All pelage measures were taken on the posterior dorsal surface. For a detailed discussion of the importance of these pelage measures on thermoregulation see McClure \& Porter (1983) and Al-Khateeb \& Johnson (1971).

Beginning at weaning, ad-libitum food intake (Purina mouse chow No. 5015) was measured twice weekly and nest size weekly as described previously (Dark \& Zucker, 1983). Briefly, food intake was measured by placing a preweighed amount of food in the hopper and then reweighing the remainder $24 \mathrm{~h}$ later. Spillage was not a problem since the young did not crumble their pellets. Nest size was measured by placing a preweighed quantity of cotton batting $(20-25 \mathrm{~g})$ on each cage lid. The batting remaining on the lid was reweighed $24 \mathrm{~h}$ later, and the amount of material removed was used as the measure of nest size. Nests were left in the cages until 2 days before the next nest-building test when fresh batting was placed on the cage lid and the procedure repeated.

At 45 days of age a lethal dose of pentobarbitone sodium was given and pelage was measured as described above. The posterior dorsal surface was then shaved clean and a $2 \mathrm{~cm}^{2}$ patch of skin removed and preserved in $10 \%$ formalin, embedded in paraffin wax, sectioned at $5 \mu \mathrm{m}$ and stained with haematoxylin and eosin. The mean number of follicles for 10 intact follicular bundles was determined microscopically for each animal.

Testes were removed, weighed and stored in $10 \%$ formalin, embedded in paraffin wax, sectioned at $5 \mu \mathrm{m}$ and stained with haematoxylin and eosin. Spermatogenesis was quantified using the 5-point Spermatogenic Index (SI) of Grocock \& Clarke (1974); an SI of 4 or 5 is indicative of full spermatogenesis and ratings of $0-3$ signify testicular development that would not support reproduction (spermatocytes, spermatids and very few spermatozoa).

Body weight and food intake were analysed with a repeated measures Analysis of Variance (ANOVA) for several group differences across all weeks; planned comparisons were then made between young in Group LD and those in each of the two short-day groups (SD-5 and SD-11), and between the two short-day groups. A multivariate ANOVA was used to analyse the pelage and nest size data. Follicle number and testes size were evaluated by ANOVA. Two-tailed probability values $\leq 0.05$ were considered statistically significant. Values are given as mean \pm s.e.m.

\section{Results}

\section{Body weight and food intake}

To minimize cannibalism young were not manipulated during the first $24 \mathrm{~h}$ of life. Within 2 days of birth male and female LD young weighed more than did those in Group SD-5 $(3.9 \pm 0 \cdot 1 \mathrm{~g}$ and $3.6 \pm 0.1 \mathrm{~g}$, respectively, $P<0.05)$, but did not differ from those of Group SD-11 $(3.9 \pm 0 \cdot 1 \mathrm{~g}$; Fig. 1). LD young were significantly heavier than those in Groups SD-5 or SD-11 by 9 days of age $(\mathrm{LD}=15 \cdot 7 \pm 0.8 \mathrm{~g}$, SD-5, SD-11 $=14.2 \pm 0.5 \mathrm{~g}$; Fig. 1). Groups SD-5 and SD-11 did not differ significantly in body weight at any time. The sex difference in body weight (males heavier than 


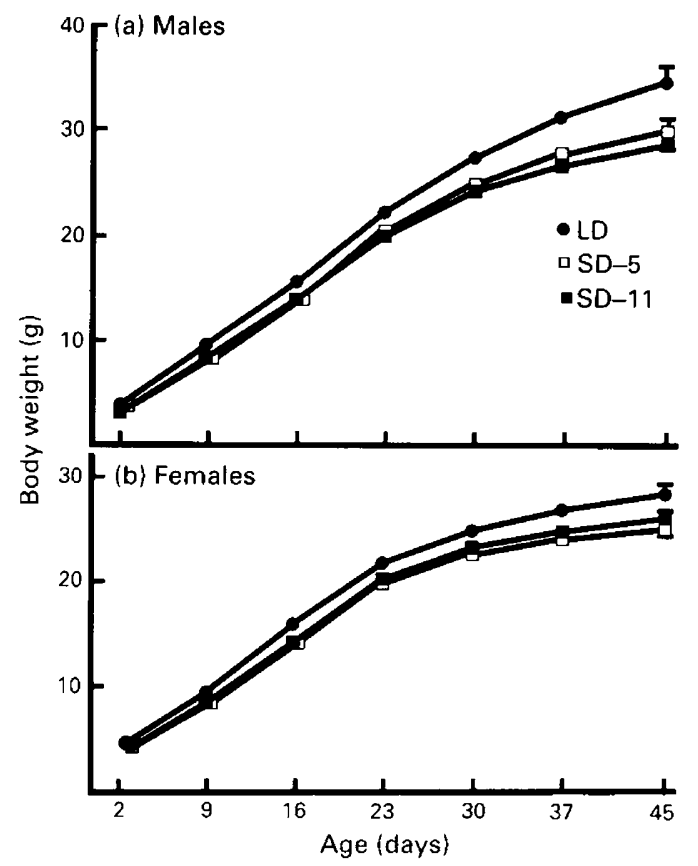

Fig. 1. Body weight at different ages for (a) male and (b) female voles maintained in long (LD) or short (SD) daylengths from the time of conception. Values are mean \pm s.e.m. for 16-26 voles/group.

females) was first significant the week after weaning for LD animals (Fig. 1, 30 days) and was apparent by 37 days for the remaining groups. By 45 days of age the male LD voles weighed $17 \%$ and $14 \%$ more than did the SD-5 and SD-11 animals, respectively, while female LD voles weighed $8 \%$ and $11 \%$ more than SD-5 and SD-11 animals, respectively.

Only in Group LD did males consume more food than did females (Table 1). Male LD young ate significantly more food between weaning and 45 days of age than did males in Groups SD-5 or SD-11. Group differences in food intake among female voles were not significant.

\section{Reproductive development}

Testicular development was significantly retarded in SD voles; testes of LD males were about twice as heavy as those of SD animals at 45 days of age. Testes of the two SD groups did not differ in weight and contained spermatogonia and spermatocytes, but very few spermatozoa; only animals in Group LD exhibited complete spermatogenesis (Table 1).

\section{Nest weight}

Nest-building did not differ amongst the groups at 28 and 35 days of age. There was no sex difference in nest-building and therefore data were combined for all young within each group. On the third and final test at 42 days of age, young in Groups SD-5 and SD-11 constructed heavier nests than did those in Group LD (Table 1).

\section{Pelage}

None of the pelage measures differed between the sexes at 21 or 45 days of age and data were combined for all young within each group. Values for fur depth, density, guard and under hair 
Table 1. Comparison of development of several measures for young reared by dams kept in long (LD) or short (SD) daylengths

\begin{tabular}{|c|c|c|c|c|}
\hline & & $\begin{array}{c}\text { Group } \\
\text { LD }\end{array}$ & $\begin{array}{l}\text { Group } \\
\text { SD-5† }\end{array}$ & $\begin{array}{l}\text { Group } \\
\text { SD-11† }\end{array}$ \\
\hline Cumulative food intake between 21 and 45 & Male & $95 \cdot 4 \pm 5 \cdot 0^{*}$ & $86 \cdot 4 \pm 3 \cdot 1$ & $86 \cdot 3 \pm 3 \cdot 8$ \\
\hline days $(\mathrm{g})$ & Female & $81 \cdot 5 \pm 3 \cdot 1$ & $82 \cdot 6 \pm 5 \cdot 0$ & $80 \cdot 2 \pm 3 \cdot 1$ \\
\hline Paired testes weight (mg) & & $807 \pm 49^{*}$ & $390 \pm 37$ & $448 \pm 4$ \\
\hline Spermatogenic Index & & $4 \cdot 8 \pm 0 \cdot 1^{*}$ & $3 \cdot 4 \pm 0.2$ & $3 \cdot 6 \pm 0 \cdot 3$ \\
\hline Nest weight at 42 days (g) & & $5 \cdot 2 \pm 0 \cdot 8^{*}$ & $7 \cdot 2 \pm 0 \cdot 8$ & $7 \cdot 7 \pm 1 \cdot 3$ \\
\hline No. of follicles/follicular bundle & & $6 \cdot 3 \pm 0.2^{*}$ & $6 \cdot 9 \pm 0 \cdot 2^{* *}$ & $7 \cdot 4 \pm 0 \cdot 1$ \\
\hline
\end{tabular}

†Dams exposed to 5 or 11 weeks of SD before parturition.

*Differs significantly from Groups SD-5 and SD-11 $(P<0.01)$.

**Differs significantly from Group SD-11 $(P<0.01)$.
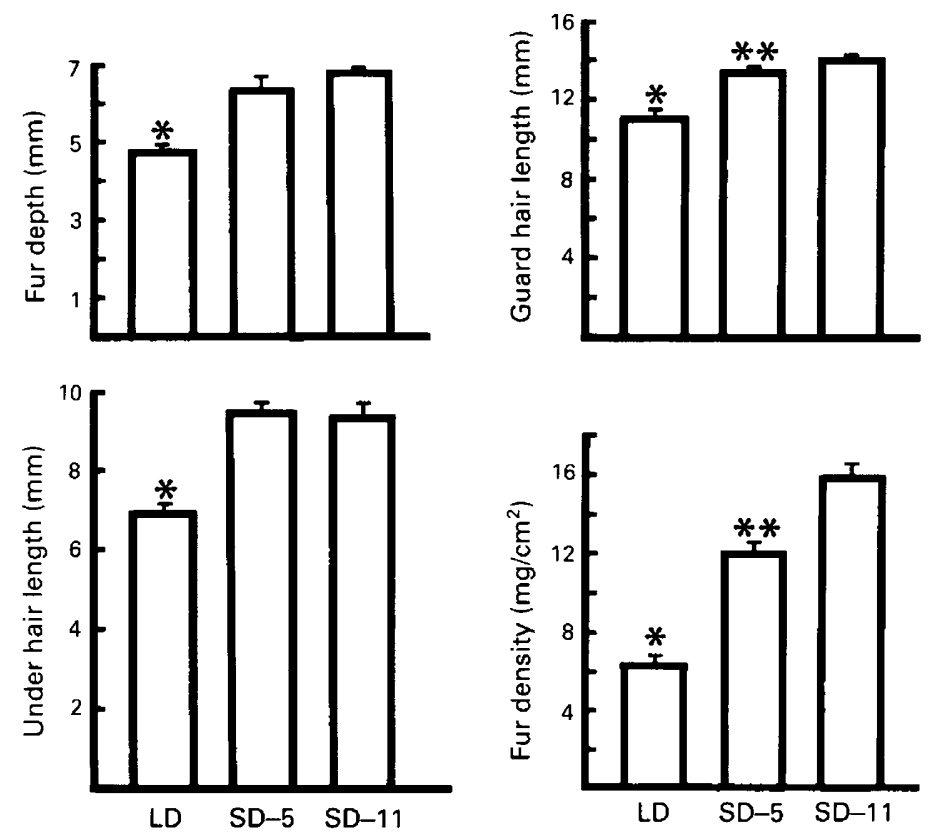

Fig. 2. Measures of fur depth, under hair and guard hair length and density at 21 days of age for young male and female voles combined after birth to dams exposed to long daylength (LD) throughout gestation and thereafter or short daylengths for 5 (SD-5) or 11 (SD-11) weeks before parturition. ${ }^{*} P<0.05$ compared with Group SD-5 and Group SD-11; ${ }^{* *} P<0.05$ compared with Group SD-11.

lengths were significantly lower at 21 and 45 days of age in LD young than in either of the SD groups (Fig. 2). The number of follicles/follicular bundle also was significantly reduced in Group LD young at 45 days af age (Table 1). Reduced pelage development of LD voles was in contrast to their increased body weight and accelerated testicular development relative to SD voles.

At 21 days of age, young in Group SD-5 had less dense fur $\left(12.0 \pm 0.6 \mathrm{mg} / \mathrm{cm}^{2}\right)$ and shorter guard hairs $(13.4 \pm 0.2 \mathrm{~mm})$ than did SD-11 voles $\left(15.9 \pm 0.8 \mathrm{mg} / \mathrm{cm}^{2}: P<0.05\right.$; and $14.1 \pm$ $0.2 \mathrm{~mm}: P<0.05$ ) (Fig. 2). At 45 days of age these groups differed only with respect to follicle number (Table 1), SD-5 voles having fewer follicles than SD-11 animals. Fur depth and under hair length did not differ between the SD groups. 


\section{Discussion}

Post-natal pelage development in vole young was affected by the photoperiodic history of their dams before mating; females kept in short daylengths for 8 as compared to 2 weeks before pairing with males produced young with fur that was more dense at weaning. Since dams and offspring in both groups were housed in the same short-day photoperiod throughout gestation, as well as after birth, pelage differences in young at 21 and 45 days of age must be due to the different photoperiodic histories of dams before insemination. The physiological means by which daylengths experienced by dams before gestation influence the offspring are unknown. In the field, it presumably is advantageous for voles that breed in mid-winter to produce young whose winter pelage develops as rapidly as possible; by contrast the offspring of voles that breed in late summer or early autumn face less severe thermoregularity challenges and have more time to develop a heavy coat. The number of short days experienced by dams before mating is greater in winter-breeders than in fall breeders and presumably affects endocrine activity in dams; this in turn may influence postnatal development of their offspring. These observations complement and extend earlier findings that dams communicate information about daylength to their fetuses (Horton, 1984, 1985).

By $48 \mathrm{~h}$ after birth, voles born to dams preadapted to short daylengths for 2 weeks weighed less than those gestated in LD (the SD-11 young were not different from LD young until 9 days of age). This effect of photoperiod may be manifested at birth, indicating that photoperiodic conditions experienced by dams during gestation affect fetal somatic development in meadow voles. Postweaning testes development and food consumption were greater, and nest-building and pelage development were decreased, in LD compared to SD males. Except for food intake, which did not differ between long- and short-day female groups, similar effects of photoperiod were observed in females and males. The design of the present experiment does not permit assessment of relative contributions of pre- and post-natal daylength in the genesis of these differences. Studies recently completed indicate that pre- and post-natal photoperiod influences the different developmental measures independently.

Short-day voles first built significantly larger nests than did LD animals at 42 days of age. Young constructed nests during the first test at 21 days of age and it is therefore unlikely that prenatal or pre-weaning photoperiod affected nest-building in newly weaned animals. The latency with which daylength affects nest-building appears to be similar in adult (Lee et al., 1987a) and weanling voles.

Young gestated and born into short days have deeper, longer and more dense pelages by 21 days of age than do young housed in long daylengths, even though the SD animals generally manifest reduced somatic growth (Dark et al., 1987) and do not undergo reproductive development. Between 21 and 45 days of age the fur continues to grow on LD and SD young, but SD young still maintain deeper, longer and more dense coats at 45 days of age; follicle number, indicative of number of hairs growing, also is substantially higher in SD than LD young.

Several adaptations that would appear to favour winter survival in vole young are influenced by the daylengths experienced by dams before and during gestation and by offspring during early postnatal life. For dams undertaking the energetically expensive task of winter breeding (see Lee $e t$ al., 1987b), survival of young is probably enhanced by accelerated pelage growth and increased nest-building, and by inhibition of somatic growth and reproductive development.

We thank Lisa Higa and Chris Tuthill for technical assistance, and Darlene Frost and Paul Haller for preparing and photographing the figures. This research was supported by NIH grant HD-02982, postdoctoral fellowship HD-06461, and NIMH traineeship MH-15860.

\section{References}

Al-Khateeb, A. \& Johnson, E. (1971) Seasonal changes of pelage in the vole (Microtus agrestis) I. Correlation with changes in the endocrine glands. Gen. comp. Endocr. 16, 217-228. 
Christian, J.J. (1980) Regulation of annual rhythms of reproduction in temperate small rodents. In Testicular Development, Structure and Function, pp. 367-380. Eds A. Steinberger \& E. Steinberger. Raven Press, New York.

Dark, J. \& Zucker, I. (1983) Short photoperiods reduce winter energy requirements of the meadow vole, Microtus pennsylvanicus. Physiol. Behav. 31, 699-702.

Dark, J., Dark, K.A. \& Zucker, I. (1987) Long day lengths increase brain weight and DNA content in the meadow vole, Microtus pennsylvanicus. Brain Res. 409, 302-307.

Fairbairn, D.J. (1977) Why breed early? A study of reproductive tactics in Peromyscus. Can. J. Zool. 55, 862-871.

Gebczynska, Z. \& Gebczynski, M. (1971) Insulating properties of nest and social temperature regulation in Clethrionomys glareolus (Schreiber). Acta zool. fenn. 8, 104-108.

Grocock, C.A. \& Clarke, J.R. (1974) Photoperiodic control of testis activity in the vole, Microtus agrestis. $J$. Reprod. Fert. 39, 337-347.

Horton, T.H. (1984) Growth and maturation in Microtus montanus: Effects of photoperiods before and after weaning. Can. J. Zool. 62, 1741-1746.

Horton, T.H. (1985) Cross-fostering of voles demonstrates in utero effect of photoperiod. Biol. Reprod. 33, 934-939.

Iverson, S.L. \& Turner, B.N. (1974) Winter weight dynamics in Microtus pennsylvanicus. Ecology 55, 1030-1041.

Lecyk, M. (1962) The effect of the length of daylight on reproduction in the field vole (Microtus arvalis). Zool. Polon. 12, 189-221.
Lee, T.M., Smale, L., Zucker, I. \& Dark, J. (1987a) Interaction of daylength and lactation in the control of pelage development and nest-building in female meadow voles (Microtus pennsylvanicus). J. Reprod. Fert. 81, 351-356.

Lee, T.M., Smale, L., Zucker, I. \& Dark, J. (1987b) Role of photoperiod during pregnancy and lactation in the meadow vole, Microtus pennsylvanicus. J. Reprod. Fert. 81, 343-350.

Martinet, L. \& Spitz, F. (1971) Variation saisonières de la croissance et de la mortalité du compagnol de champs, Microtus arvalis. Rôle du photopériodisme et de la végétation sur ces variations. Mammalia 35, 38-84.

McClure, P.A. \& Porter, W. (1983) Development of insulation in neonatal cotton rats (Sigmodon hispidus). Physiol. Zool. 56, 18-32.

Negus, N.C., Berger, P.J. \& Brown, B.W. (1986) Microtine population dynamics in a predictable environment. Can. J. Zool. 64, 785-792.

Petterborg, L.J. (1978) Effect of photoperiod on body weight in the vole Microtus montanus. Can. J. Zool. 56, 431- 435 .

Pistole, D.H. \& Cranford, J.A. (1982) Photoperiodic effects on growth in Microtus pennsylvanicus. $J$. Mammal. 63, 547-553.

Spears, N. \& Clarke, J.R. (1986) Effect of male presence and of photoperiod on the sexual maturation of the field vole (Microtus agrestis). J. Reprod. Fert. 78, 231-238. 